Portland State University

PDXScholar

$5-20-2016$

\title{
Assessing Wind Energy Potential for Vertical Axis Wind Turbines on the Tilikum Crossing
}

Clint Everett

Portland State University

Follow this and additional works at: https://pdxscholar.library.pdx.edu/honorstheses

Let us know how access to this document benefits you.

\section{Recommended Citation}

Everett, Clint, "Assessing Wind Energy Potential for Vertical Axis Wind Turbines on the Tilikum Crossing" (2016). University Honors Theses. Paper 302.

https://doi.org/10.15760/honors.256

This Thesis is brought to you for free and open access. It has been accepted for inclusion in University Honors Theses by an authorized administrator of PDXScholar. Please contact us if we can make this document more accessible: pdxscholar@pdx.edu. 
Assessing wind energy potential for vertical axis wind turbines on the Tilikum Crossing

by

Clint Everett

A thesis submitted in partial fulfillment of the requirements for the degree of

\author{
Bachelor of Science \\ in \\ Mechanical Engineering
}

Thesis Advisor

Raúl Bayoán Cal

Portland State University

2016 


\begin{abstract}
Wind energy is a growing sector of renewables, and small wind is a key area for growth. In Portland, Oregon small scale vertical axis wind turbines (VAWTs) will be installed on the Tilikum Crossing bridge. Prior to turbine installation, a wind resource assessment was conducted to provide details about the wind environment turbines will placed in. For seven months, 12 instruments collected wind and weather data for analysis. Data was analyzed between different locations and over various time scales. Trends pointed to wind dominantly coming from the South and also frequently from the North, generally following the channel of the Willamette River. Month to month, wind speeds fluctuated minimally; however, day to day, wind speeds increase significantly during the daytime hours. For several measuring stations, close proximity to a structure caused reductions in speed compared to stations further away. On the bridge, high levels of turbulence are present, but wind speeds tend to be very low. Based on these findings it will be difficult to generate power from VAWTs because turbines require higher wind speeds.
\end{abstract}




\section{Contents}

Abstract $\quad$ i

List of Figures iv

1 Introduction 1

1.1 Motivation and Background ................ 1

1.2 Previous Wind Resource Assessments . . . . . . . . . . . . . . 4

$\begin{array}{lll}2 & \text { Computations } & 7\end{array}$

2.1 Frequency and Cumulative Probability Distributions . . . . . . . . 7

2.2 Wind Rose ....................... 8

2.3 Correlation Matrix . . . . . . . . . . . . . . . 9

2.4 Average Wind Speeds . . . . . . . . . . . . . . . . 9

2.5 Diurnal Cycle . . . . . . . . . . . . . . . . . 10

2.6 Turbulence Intensity . . . . . . . . . . . . . . . . . . . . . . . . . . 10

3 Instrumentation and Data $\quad 12$

3.1 Location and Instrumentation . . . . . . . . . . . . . . . . . 12

3.2 Data Collection . . . . . . . . . . . . . . . 16

3.3 Data Signal . . . . . . . . . . . . . . . . . 18 
3.4 Data Omission . . . . . . . . . . . . . . . . . 19

4 Results and Discussion $\quad 20$

4.1 Frequency Distribution . . . . . . . . . . . . 20

4.2 Cumulative Probability Distribution . . . . . . . . . . . . . 22

4.3 Wind Rose ....................... 24

4.4 Correlation Matrix . . . . . . . . . . . . . 25

4.5 Average Wind Speeds . . . . . . . . . . . . . . . 27

4.6 Diurnal Cycle . . . . . . . . . . . . . . . . . . . 29

4.7 Turbulence Intensity . . . . . . . . . . . . . . . . . . . 30

5 Conclusion $\quad 31$ 


\section{List of Figures}

1.1 UGE HoYi! vertical axis wind turbine . . . . . . . . . . . . 2

1.2 Tilikum Crossing spanning Willamette River looking south . . . . . 3

2.1 Sample wind rose from $[1] \ldots \ldots \ldots$

3.1 Satelite image of Willamette Valley and surrounding moutains . . . 13

3.2 Measuring station locations on Tilikum Crossing . . . . . . . . . . 14

3.3 Measuring instruments installed on Tilikum Crossing . . . . . . . . 15

3.4 Weatherlink interface . . . . . . . . . . . . . 17

3.5 Raw wind speed signal over sevel months of data collection . . . . . 18

4.1 Frequency distributions ................ 21

4.2 Cumulative probability distributions . . . . . . . . . . 23

4.3 Wind roses for nine measuring stations, four western and five eastern 25

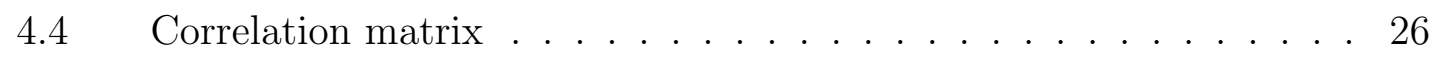

4.5 Average wind speeds . . . . . . . . . . . . . . 27

4.6 Monthly average wind speeds . . . . . . . . . . . . 28

4.7 Diurnal cycle . . . . . . . . . . . . . . . . . . . . . . . . . 29

4.8 Turbulence intensity . . . . . . . . . . . . . . 30 


\section{Chapter 1}

\section{Introduction}

\subsection{Motivation and Background}

In 2015 renewable energy provided the US with $10 \%$ of its consumed energy, and only $1.9 \%$ of energy came from wind [2]. By comparison, Denmark consumed $42 \%$ of its energy from wind power in the same year [3]. Globally, installed wind capacity has increased by nearly 25 times from 2000 to 2015, and it grows by larger amounts each year [4]. Wind energy plays a vital role in the global push for a renewable energy future, and there is vast opportunity for growth in the United States.

Most often wind energy comes from wind farms with horizontal axis wind turbines (HAWT) approaching $100 \mathrm{~m}$ in height. These are located in rural areas away from cities; however, wind energy can also be produced in urban environments. Cities by nature do not have a lot of open space, so for turbines to be used they must become smaller. These types of turbines form a segment of wind energy called small wind, where turbines are between 9 and $40 m$ tall with capacity ratings lessthan-or-equal-to $100 \mathrm{~kW}[5,6]$. Traditional turbines generally have capacities in the multi-megawatt range.

For small wind applications vertical axis wind turbines (VAWTs) become an 
increasingly popular option. They have blades that spin around a vertical axis (Figure 1.1) eliminating the need for complex yaw control systems used by HAWTs to rotate their blades into the wind [7]. VAWTs can receive wind from any direction to produce power. This is important in urban environments because urban obstacles like plants, cars, and buildings work to create turbulence and irregularities in wind flow patterns. Being able to accommodate wind from any direction helps VAWTs perform better in turbulent wind conditions [8]. In Portland, Oregon, TriMet is considering these advantages in its most recent public transit expansion project.

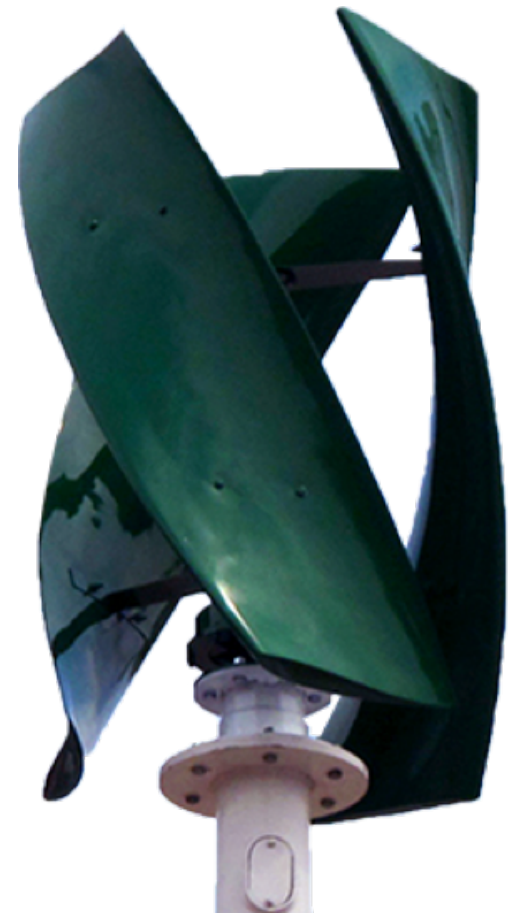

Figure 1.1: UGE HoYi! vertical axis wind turbine

Late in 2015 the Tilikum Crossing (Figure 1.2) opened in Portland as a part of the TriMet Portland-Milwaukie Light Rail Transit Project. It is a transit-only bridge open to buses, light rail trains, streetcars, cyclists, and pedestrians. TriMet 
is the regional public transit provider and holds ownership of the bridge. At the heart of the project is a theme of sustainability, and this includes implementing technologies in new ways like installing VAWTs on the Tilikum Crossing [9].

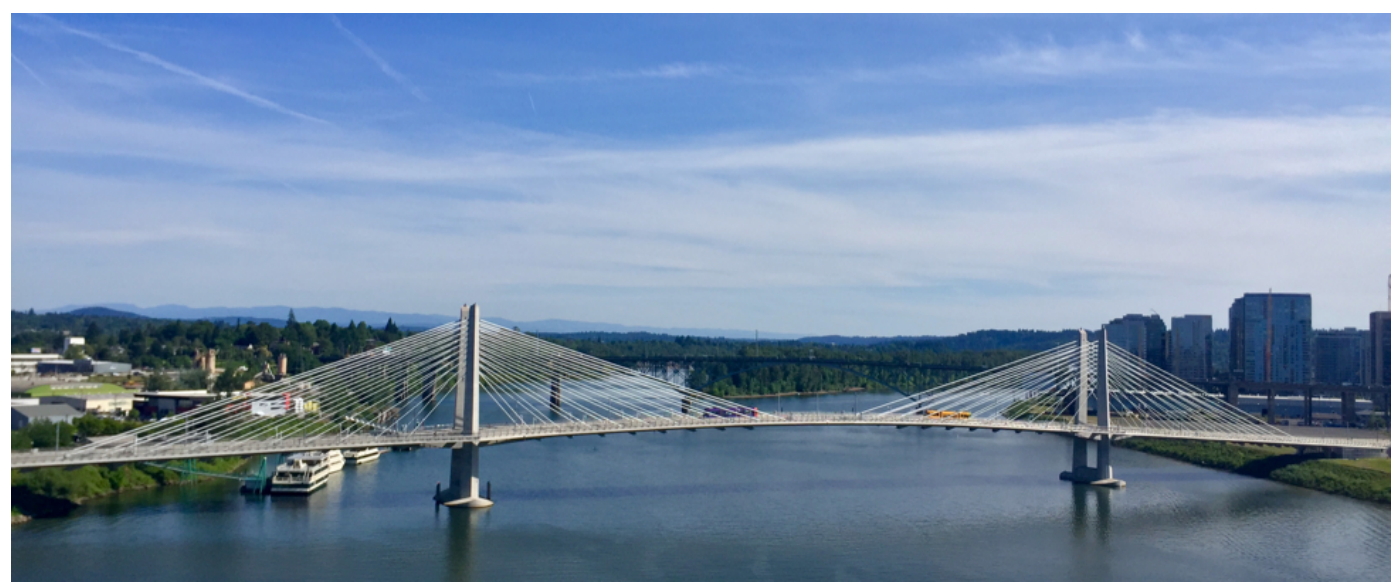

Figure 1.2: Tilikum Crossing spanning Willamette River looking south

Prior to implementing VAWTs though, it is also important to consider the wind resource powering these wind turbines. Wind behavior changes depending on the physical location and the time that it is being observed. Time-wise, there are synoptic variations due to passing storms, diurnal, seasonal, and even variations over many years [10]. Geographical impacts at a global scale and a local scale change wind behavior. Wind is driven mostly by energy from the sun and the associated temperature differences that cause circulation of air in the atmosphere. Coastal regions are often windier because of the way land and sea are heated differently by the sun. Hilltops can experience accelerated wind speeds due to their higher reaches into the surface boundary layer, and valleys can act as funnels for wind to gain speed [10]. Even urban and rural locations differ with complex urban structures and obstacles adding turbulence to wind flow. All of these contribute to uncertainty 
in wind behavior. When working to quantify the wind resource available to VAWTs on the Tilikum Crossing, a wind resource assessment is conducted.

\subsection{Previous Wind Resource Assessments}

Wind studies in recent years have concluded a variety of different findings. A study of Chalus County in Iran, incorporating 14 months of data, looked into the feasibility of using a Bergey XL.1 turbine. Finding that monthly mean wind speeds reached the cut-in speeds seven months out of the year, the authors concluded that the location is not good for wind energy generation [11]. Jowder studied the Kingdom of Bahrain using a vertical extrapolation computation to extend measurements from $10 \mathrm{~m}$ height to 30 and $60 \mathrm{~m}$. Then power and capacity factor predictions for several different turbines were calculated, leading to conclusions that the Mod-0 turbine and Gamesa G58 turbines are recommended for installation heights of 30 and 60 $m$, respectively [12]. Janajreh et al. performed a similar study in Masdar City of the United Arab Emirates and found that a smaller 3.5 KW Windspot turbine would perform better than a much larger Nordtank 500/41 turbine. This is based on capacity factors of $7.39 \%$ for the Windspot at $30 \mathrm{~m}$ versus $5.15 \%$ for the Nordtank [13]. A study of Kirklareli, Turkey represents wind data using frequency distribution and cumulative probability distribution based on observed data. It concludes that Kirklareli is a marginal area for wind power generation [14]. Ucar et al. studied six locations in turkey and found that Erzurum and Elazig are the best regions for power generation when considering implementation of the De Wind D8 turbine [15].

Several articles conducted wind assessments while also looking into the performance of certain computations. A 2010 study of central Finland by Saengyueny- 
ongpipat employs measure-correlate-predict (MCP) methods to determine their effectiveness. Measure-correlate-predict methods use a short term data set, attempt to correlate it to another long term data set, and use that correlated relationship to predict long term wind data for the original site. Two methods were used to determine missing data between two locations and results showed that MCP can successfully predict missing data. For the sites however, they were determined best suitable for small-scale power production [16]. Rehman et al. conducted a study in Dhulom, Saudi Arabia and focused part of their wind assessment on wind shear coefficients and how they change. They found no seasonal pattern to wind shear coefficient variation, and for wind turbines, they concluded at $40 \mathrm{~m}$ hub-height turbines with a $4 \mathrm{~m} / \mathrm{s}$ cut-in speed can produce energy nearly $75 \%$ of the time [1].

Wind studies have also been performed with a focus on urban environments. A wind assessment in the Braşov region of Romania compared an urban site and a rural site. Average wind speeds were $1.13 \mathrm{~m} / \mathrm{s}$ and $2.03 \mathrm{~m} / \mathrm{s}$, respectively [17]. Sunderland et. al. study of urban wind in Dublin, Ireland compared the predicted power outputs of an airport, an urban location, and a suburban location. The comparisons were based on a Wind Energy Solutions Tulipo turbine rated at a capacity of $2.5 \mathrm{~kW}$ with a $3 \mathrm{~m} / \mathrm{s}$ cut-in speed. They found that at the airport it could produce $5892 k W h$ with a capacity factor of $42 \%$, exceeding the $5000 k W h$ average Irish domestic energy need. The urban and suburban locations performed half as well with capacity factors of $20 \%$ and predicted outputs of $2445 \mathrm{kWh}$ and 2672 $k W h$, respectively [18]. Another study in the heavily urban city-state of Singapore studied three locations with building-anemometers at heights between 64 and $83 \mathrm{~m}$. By focusing on 10-minute interval observations of wind speed, turbulence intensity 
(TI) was able to be calculated from the mean and standard deviation for those intervals, leading to the finding that TI decreases as wind speed increases. Also using LiDAR to detect TI at different heights, it was uniform between 2 and $8 \mathrm{~m} / \mathrm{s}$, and then increased with greater wind speeds [19]. 


\section{Chapter 2}

\section{Computations}

\subsection{Frequency and Cumulative Probability Distributions}

A frequency distribution is useful for identifying which wind speeds occur most often. It is created by separating wind speed into equally sized bins. Then the probability of occurence for each bin is computed using Equation 2.1::

$$
p_{i}=\frac{m_{i}}{N_{t}} * 100
$$

where $i$ represents bins corresponding to wind speed values $\left(0,1,2\right.$ etc.), $m_{i}$ is the number of measurements per bin, $N_{t}$ is the total number of measurements recorded, and $p_{i}$ is the probability of occurrence for each bin. Probability is plotted on the vertical axis versus wind speed on the horizontal axis.

A cumulative probability distribution builds on the frequency distribution showing the percentage of the time wind will blow at a speed less-than-or-equal-to a given value. Individual probabilities used in the frequency distribution are summed from $0 \mathrm{~m} / \mathrm{s}$ up to the specific wind speed bin through Equation 2.2:

$$
c_{i}=\sum_{j=0}^{n=j} p_{i}
$$


where $c_{i}$ is the cumulative probability for each bin. As an example, this plot would show that wind speed is $\leq 2 \mathrm{~m} / \mathrm{s}$ approximately $50 \%$ of the time. By nature, at the highest wind speed bin there will be a cumulative probability of $100 \%$.

\section{$2.2 \quad$ Wind Rose}

A wind rose plots the frequency distribution for wind blowing with equally spaced wind direction sectors. Figure 2.1 shows wind direction bin sizes of $30^{\circ}$. In this study, wind direction bins of $22.5^{\circ}$ will be used creating 16 sectors. The radial arms of the wind rose vary in length and correspond to the total fraction from that direction. Within each radial arm are segments representing wind speed bins shown in the legend. The radial length of these bins corresponds to the total fraction of wind in that bin.

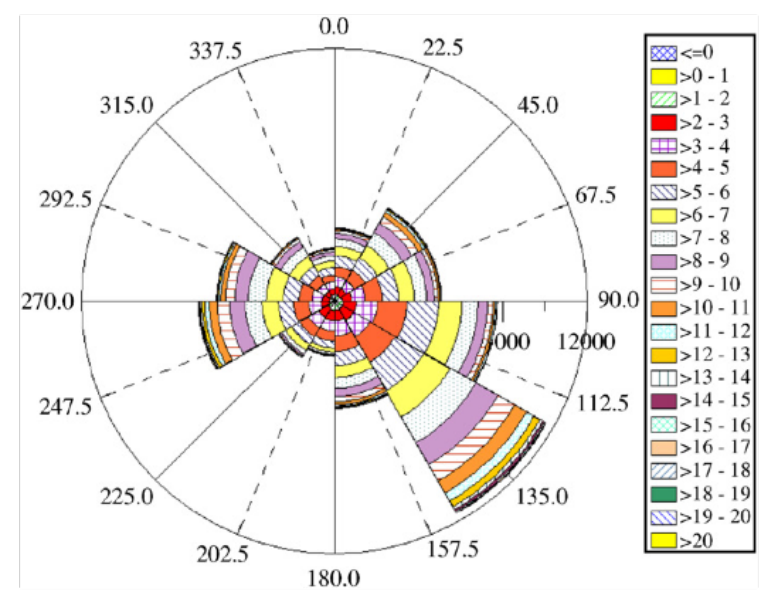

Figure 2.1: Sample wind rose from [1] 


\subsection{Correlation Matrix}

Incorporating wind and weather variables, a correlation matrix highlights important relationships between them. It is defined by Equation 2.3 where two variables $x$ and $y$ are compared, and given by,

$$
r=\frac{\sum_{j=1}^{n}\left(x_{j}-\bar{x}\right)\left(y_{j}-\bar{y}\right)}{\sqrt{\left(\sum_{j=1}^{n}\left(x_{j}-\bar{x}\right)^{2}\right)\left(\sum_{j=1}^{n}\left(y_{j}-\bar{y}\right)^{2}\right)}} .
$$

$r$ is the correlation coefficient, $n$ is the number of samples, $x_{j}$ and $y_{j}$ are the iterative samples, and $\bar{x}$ and $\bar{y}$ are the means of each sample. The correlation coefficient identifies the extent to which two variables have a positive or negative linear correlation. An $r$ of +1 is a perfect positive linear correlation with both variables increasing in magnitude together. Conversely, an $r$ of -1 is a perfect negative linear correlation where one variable decreases as the other increases. When implemented, the correlation matrix utilizes a color-bar legend to represent the strength of correlation.

\subsection{Average Wind Speeds}

Computing average wind speeds helps quickly describe any differences between measuring locations. Breaking down further to monthly averages highlights changes that occur between locations as the year progresses (Equation 2.4 [12]):

$$
\bar{V}=\frac{1}{N}\left[\sum_{j=1}^{N} V_{j}\right]
$$

In the equation above $\bar{V}$ is the average wind speed for a specified time frame, $N$ is the total number of measurements for that time frame, and $V_{j}$ is the wind speed 
recording.

\subsection{Diurnal Cycle}

The diurnal cycle shows the average wind cycle for a 24-hour period. Hour of the day is plotted on the horizontal axis and wind speed is plotted on the vertical axis. As time progresses through a day temperature is known to change with the exposure of sunlight, and it has been shown that wind speed tends to do the same [17]. As air warms during the day, convection begins to have a greater impact on wind patterns with hot air rising and cold air sinking. For this computation, Equation 2.4 can be adapted to recurring daily measurements. One bin is created for each hour of the day, and all wind speed measurements recorded for that hour are averaged together for all days that data is measured.

\subsection{Turbulence Intensity}

Turbulence intensity (TI) is a measurement of the turbulence in a wind stream [10]. It provides a metric of how aggressive the changes in wind speed are. Higher TI corresponds to larger magnitude fluctuations in the wind [1]. It is caused mainly by friction due to obstacles across the surface of the earth and thermal effects. Turbulence has been shown to increase in urban environments [17], and it may also account for decreased power production in wind turbines, making it an important quantity to track [20]. Because turbulence is a very complex quantity to measure it is more efficient to use a statistical approach. Turbulence intensity can be measured by Equation 2.5 [10]: 


$$
T I=\frac{\sigma}{\mu}
$$

where $\sigma$ is the wind speed standard deviation and $\mu$ is the average wind speed. In this study TI is computed using hourly intervals, and then these are averaged to a final turbulence intensity value. TI is computed most accurately with smaller time intervals. 


\section{Chapter 3}

\section{Instrumentation and Data}

\subsection{Location and Instrumentation}

The Tilikum Crossing spans the Willamette River near its mouth, where it empties into the Columbia River. The Willamette Valley is surrounded by two large mountain ranges: The Cascades to the east and the Coastal Range to the west (Figure 3.1). Situated about $105 \mathrm{~km}$ from the Pacific Ocean, Portland is impacted by weather systems from the Pacific year-round. Often these systems are mild bringing light to moderate rains and cloudy weather during the winter months. Summers have little rain and are often very sunny [21]. Tornadoes and extreme weather events are rare. 


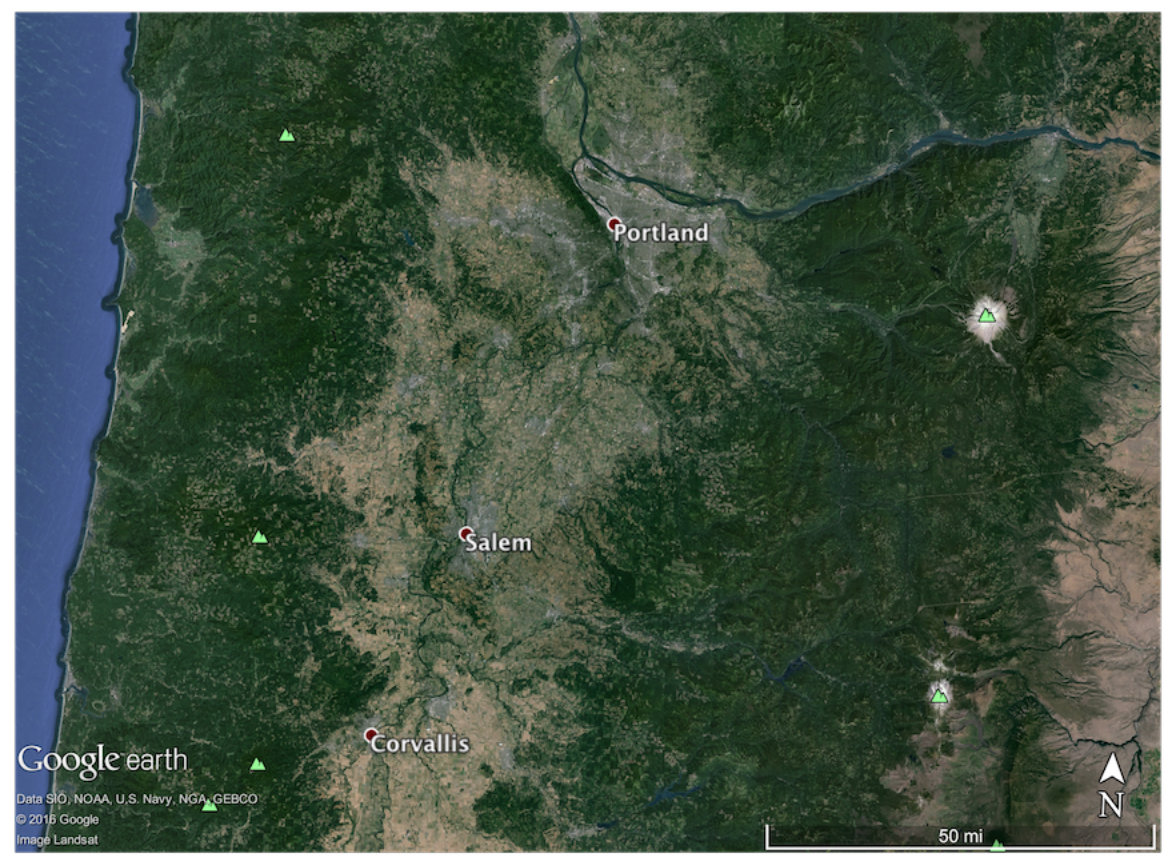

Figure 3.1: Satelite image of Willamette Valley and surrounding moutains

Narrowing to the city limits many hills and buttes with heights ranging from 120 $m$ to several hundred meters spread across Portland east of the Tilikum Crossing. To the west, a range known as the Tualatin Mountains runs north and south along the western bank of the Willamette River and the Columbia River for many kilometers. The range reaches heights as large as $320 \mathrm{~m}$ and comes to within a kilometer of the bridge at its southern end [22]. The bridge itself is about $500 \mathrm{~m}$ long. On the western end, the Collaborative Life Sciences Building is a large structure just to the North (Figure 3.2(A)), and on the eastern approach the Portland Opera building is just to the south. 


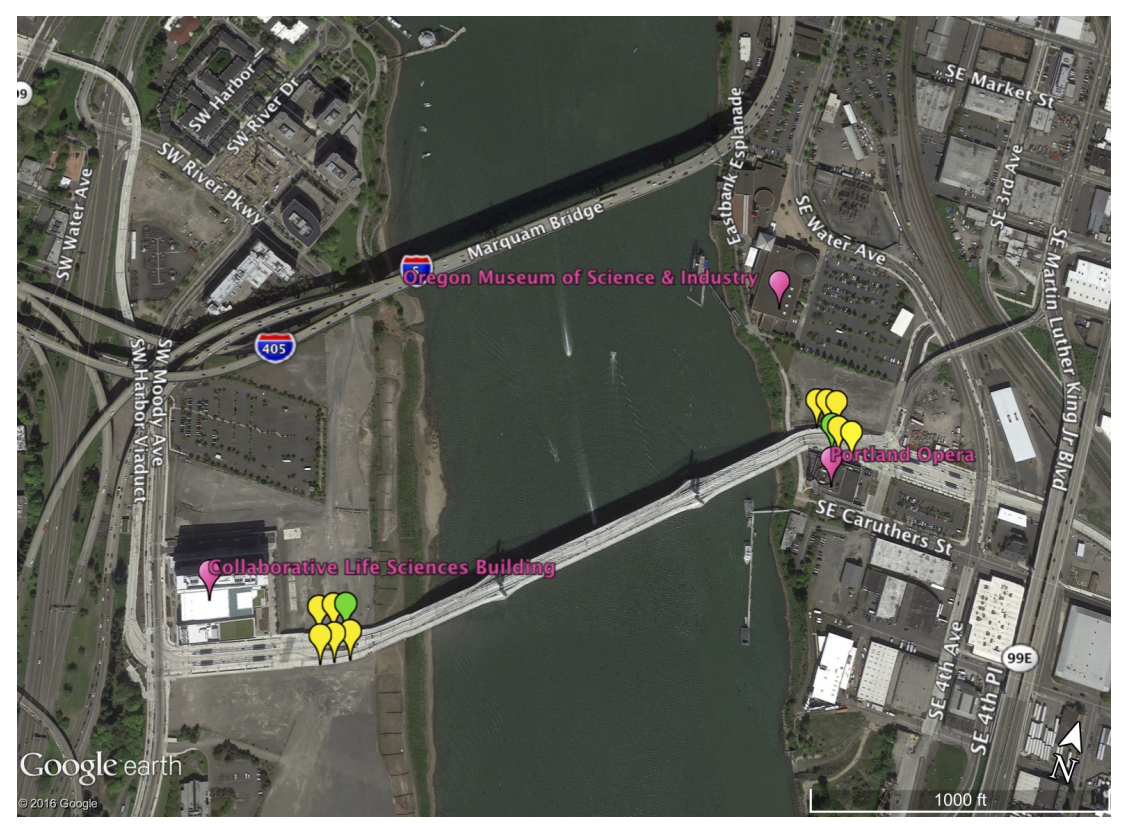

(A) All measuring stations

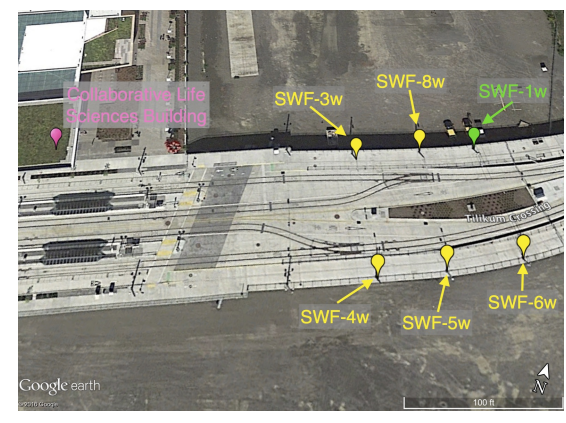

(B) West stations

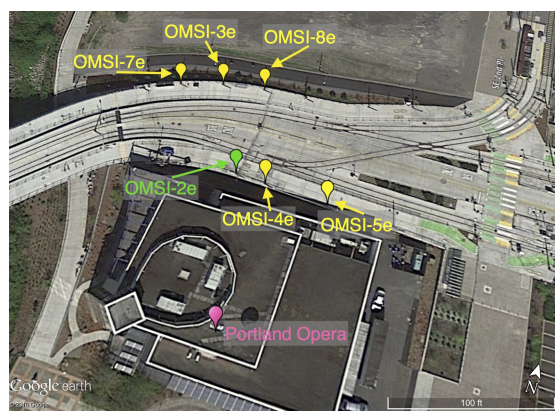

(C) East stations

Figure 3.2: Measuring station locations on Tilikum Crossing

During the summer of 2015 TriMet installed 12 measuring devices on the bridge, all produced by Davis Instruments. They are installed on $10 \mathrm{~m}$ tall support poles. Each approach is equipped with a Vantage Vue weather station (Figure 3.3(A)) capable of measuring wind speed, wind direction, temperature, humidity, and rain amounts. Five additional Anemometer for Vantage Pro2 cup anemometers (Figure 
3.3(B)) are located on either side of the bridge recording wind speed and wind direction. Weather stations are shown as green markers in Figure 3.2 and anemometers are yellow markers.

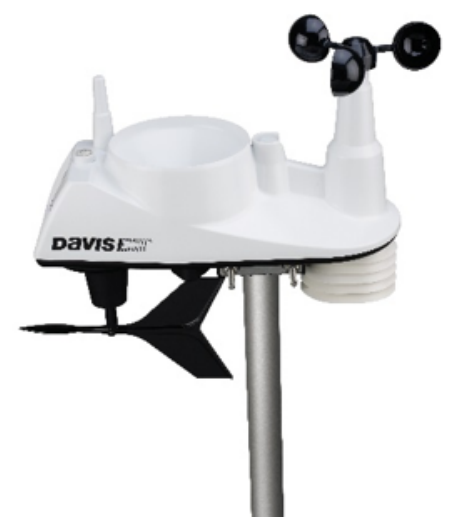

(A) Vantage Vue

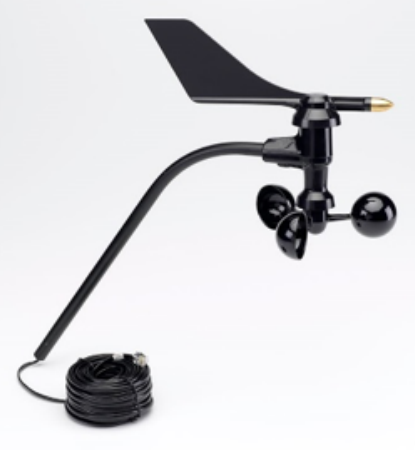

(B) Anemometer for Vantage Pro2

Figure 3.3: Measuring instruments installed on Tilikum Crossing

Data from the measuring devices is routinely uploaded to Davis' WeatherLink server. Instrument resolution and accuracy for the weather stations and anemometers is located in Table 3.1 and Table 3.2 for the Vantage Vue and Anemometer for Vantage Pro2, respectively. For both measuring devices, the major wind and weather variables are listed with the resolution that the measurements are recorded in and their range of accuracy. These instruments are inexpensive solutions compared to those implemented in other studies. High quality instruments with wind speed resolutions of $1 \mathrm{~mm} / \mathrm{s}$ have been used in studies like [18], however, the study also used the Vantage Vue. [16] used the Davis Vantage Pro as their primary instrument. Ultimately the current instruments are good selections for an initial wind study. 
Table 3.1: Vantage Vue instrument resolution and accuracy

\begin{tabular}{|c|c|c|}
\hline Variable & Resolution & Accuracy \\
\hline Wind Speed & $1 \mathrm{mph}$ & $\begin{array}{l} \pm 2 \text { mph or } 5 \% \text {, whichever } \\
\text { is greater }\end{array}$ \\
\hline Wind Direction & $\begin{array}{l}1^{\circ}, \text { recorded as, } 16 \text { points } \\
\text { on compass rose }\end{array}$ & $\pm 3^{\circ}$ \\
\hline Temperature & $0.1^{\circ} \mathrm{F}$ & $\pm 1^{\circ}$ \\
\hline Humidity & $1 \%$ & $\begin{array}{l} \pm 3 \% \text { relative humidity or } \\
\pm 4 \% \text { when above } 90 \%\end{array}$ \\
\hline Pressure & $0.01 \mathrm{in}-\mathrm{Hg}$ & \pm 0.03 in-Hg \\
\hline
\end{tabular}

Table 3.2: Anemometer for Vantage Pro2 instrument resolution and accuracy

\begin{tabular}{|l|l|l|}
\hline Variable & Resolution & Accuracy \\
\hline Wind Speed & $1 \mathrm{mph}$ & $\begin{array}{l} \pm 2 \mathrm{mph} \text { or } 5 \%, \text { whichever } \\
\text { is greater }\end{array}$ \\
\hline Wind Direction & $\begin{array}{l}1^{\circ}, \text { recorded as16 points } \\
\text { on compass rose }\end{array}$ & $\pm 3^{\circ}$ \\
\hline
\end{tabular}

\subsection{Data Collection}

Data is downloaded weekly using proprietary WeatherLink software from Davis Instruments. It is then exported into a tab-delimited format for processing. Data is recorded in 5-minute time-average intervals. During a 5-minute time-averaged period multiple measurements are taken and averaged together; the time gap between them depends on the variable. For the Vantage Vue, wind speed and direction readings are taken every 2.5-3 s. Temperature readings are taken every 10-12 s, while humidity and pressure readings are taken every minute. Anemometer for Vantage Pro2 readings are taken approximately every 3 seconds. Figure 3.4 provides a visual of the data presentation interface incorporated into the software. In the graph, time is along the horizontal axis for one month of data. The axis can be expanded or shrunk to display different time scales. On the vertical axis wind speed is plotted. 
The bottom bar contains multiple variables that can be selected for display in the interface. Data records begin with measurements from August 29, 2015, and all measuring devices were collecting data by September 11, 2015.

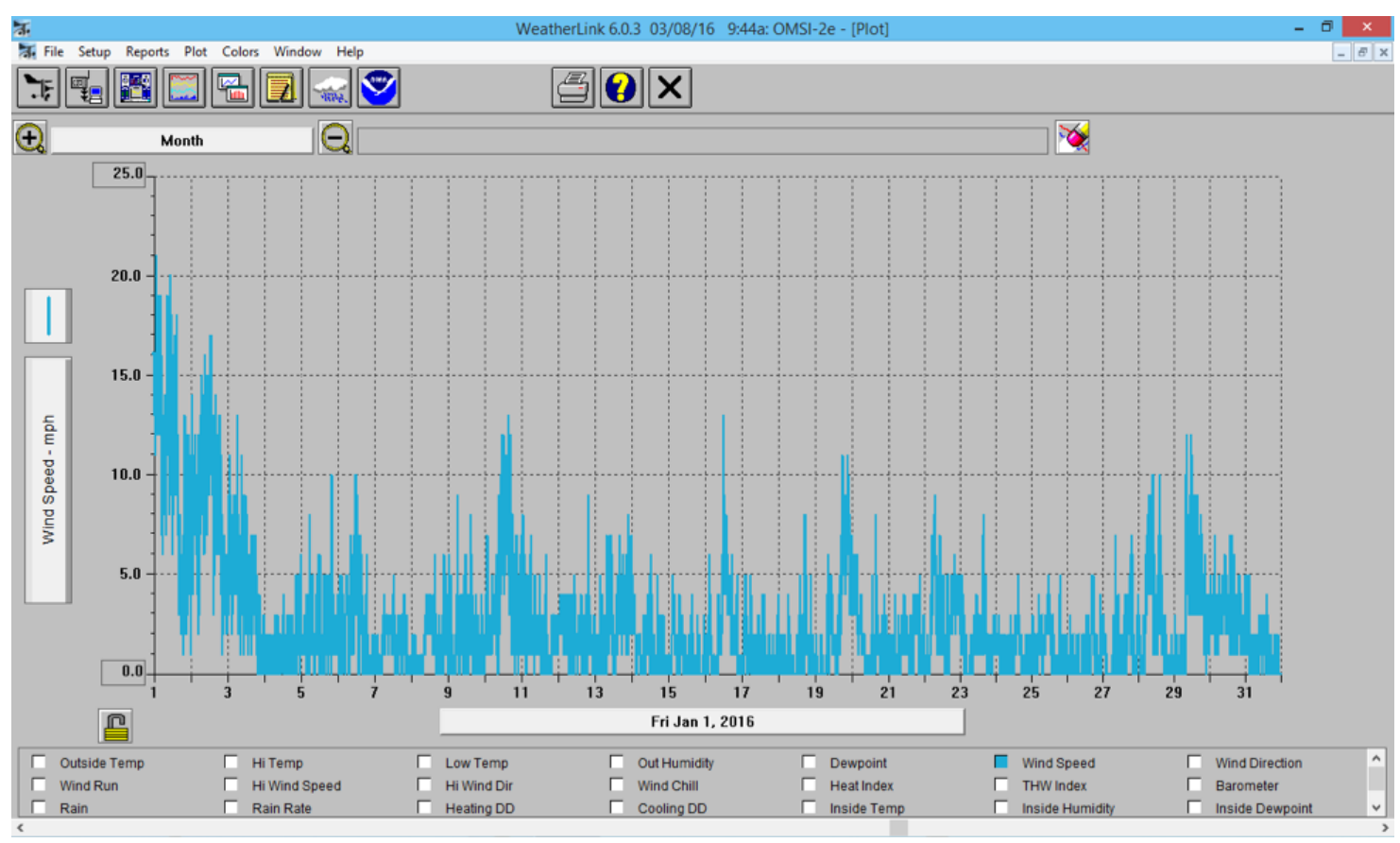

Figure 3.4: Weatherlink interface

Each of the 12 data sets is named so it is easily identified based on location and measuring device type. This naming convention comes in useful when discussing data omission. SWF represents South Water Front and corresponds the western approach to the Tilikum Crossing; OMSI represents Oregon Museum of Science and Industry and corresponds to the eastern approach to the Tilikum Crossing. 
Table 3.3: Measuring station naming conventions

\begin{tabular}{|l|l|l|}
\hline Instrument type & Western approach & Eastern approach \\
\hline weather station & SWF-1w & OMSI-2e \\
\hline anemometer & SWF-3w & OMSI-3e \\
\hline anemometer & SWF-4w & OMSI-4e \\
\hline anemometer & SWF-5w & OMSI-5e \\
\hline anemometer & SWF-6w & OMSI-7e \\
\hline anemometer & SWF-8w & OMSI-8e \\
\hline
\end{tabular}

\subsection{Data Signal}

Data is exported from WeatherLink and imported into MATLAB for analysis. Figure 3.5 shows an example of the raw wind speed signal.

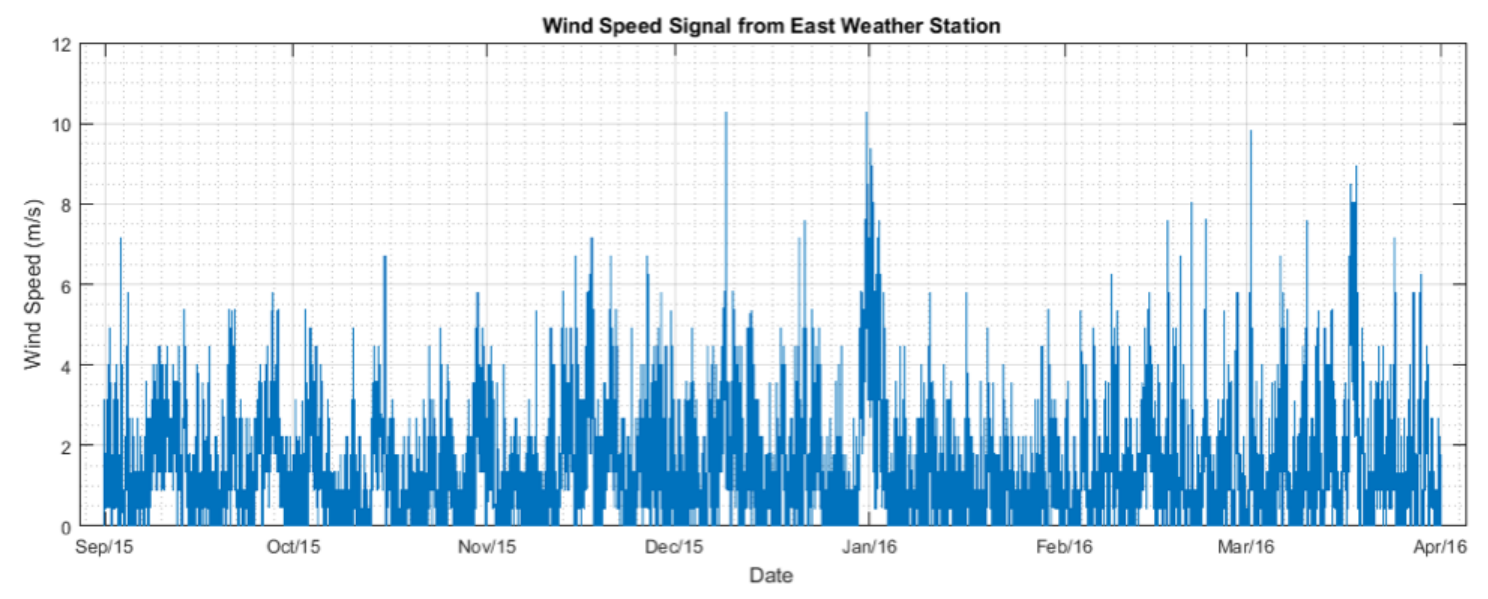

Figure 3.5: Raw wind speed signal over sevel months of data collection

When the data signal is received, it is recorded in English units. Wind speed is recorded in integer units of miles-per-hour. All further computations work with wind speed in Metric units of meters-per-second. Wind direction data is recorded in 16 compass rose directions. It is converted to degrees for use in computations. 


\subsection{Data Omission}

Ten measuring stations experienced errors leading to the omission of data from analysis. SWF-4w is excluded from all analysis because a significant amount of data is missing in the months of February and March due to data recording failures. Additionally, during September and October wind speed was not recorded. Direction data for SWF-3w and OMSI-2e are omitted. The wind vane for SWF-3w appears to have been stuck in one position for several months, and OMSI-2e does not report wind directions due North or due South.

Data recording failures are also heavily present in the western measuring stations with multiple failures spanning several days or more. There are some data recording failures for eastern measuring stations as well. Table 3.4 shows the percentage of total data records omitted for each measuring station.

Table 3.4: Vantage Vue instrument resolution and accuracy

\begin{tabular}{|l|l|}
\hline Measuring Station & Percentage of Data Failures \\
\hline SWF-1w & 14.6 \\
\hline SWF-3w & 14.6 \\
\hline SWF-4w & N/A \\
\hline SWF-5w & 15.6 \\
\hline SWF-6w & 14.9 \\
\hline SWF-8w & 15.6 \\
\hline OMSI-2e & 0 \\
\hline OMSI-3e & $<<1$ \\
\hline OMSI-4e & $<<1$ \\
\hline OMSI-5e & 0 \\
\hline OMSI-7e & 1 \\
\hline OMSI-8e & 0.4 \\
\hline
\end{tabular}




\section{Chapter 4}

\section{Results and Discussion}

\subsection{Frequency Distribution}

Frequency distributions consider all valid data records. Figure 4.1 shows frequency distributions for west and east measuring stations. Wind speed magnitude is recorded on the horizontal axis and frequency of occurrence on the vertical axis in terms of percentage. Each profile represents a different station. Western stations experience peak frequencies for wind speeds between 0 and $2 \mathrm{~m} / \mathrm{s}$, with the exception of SWF-6w peaking between 2 and $3 \mathrm{~m} / \mathrm{s}$. Calm conditions occur infrequently, about $3 \%$ of the time for the anemometers. Eastern measuring stations also experience peak frequencies between 0 and $2 \mathrm{~m} / \mathrm{s}$. Calm conditions occur infrequently between 2 and $6 \%$ of the time, depending on the anemometer. For the weather

stations, calm conditions occured more frequently at 9 and $15 \%$ for the west and east sides, respectively. Overall, wind speeds are rarely above $6 \mathrm{~m} / \mathrm{s}$. 


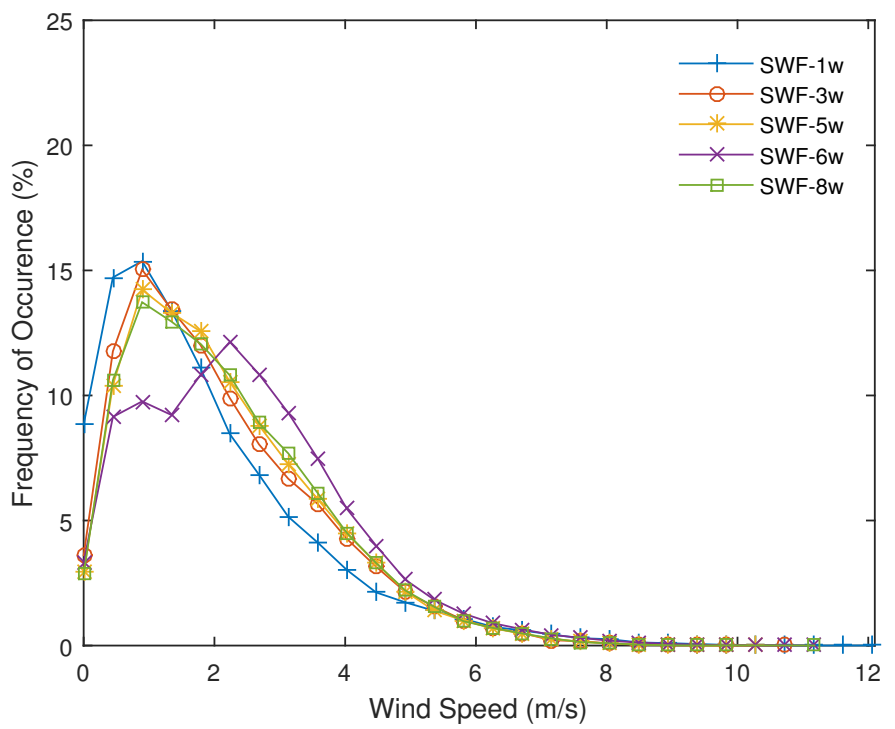

(A) West stations

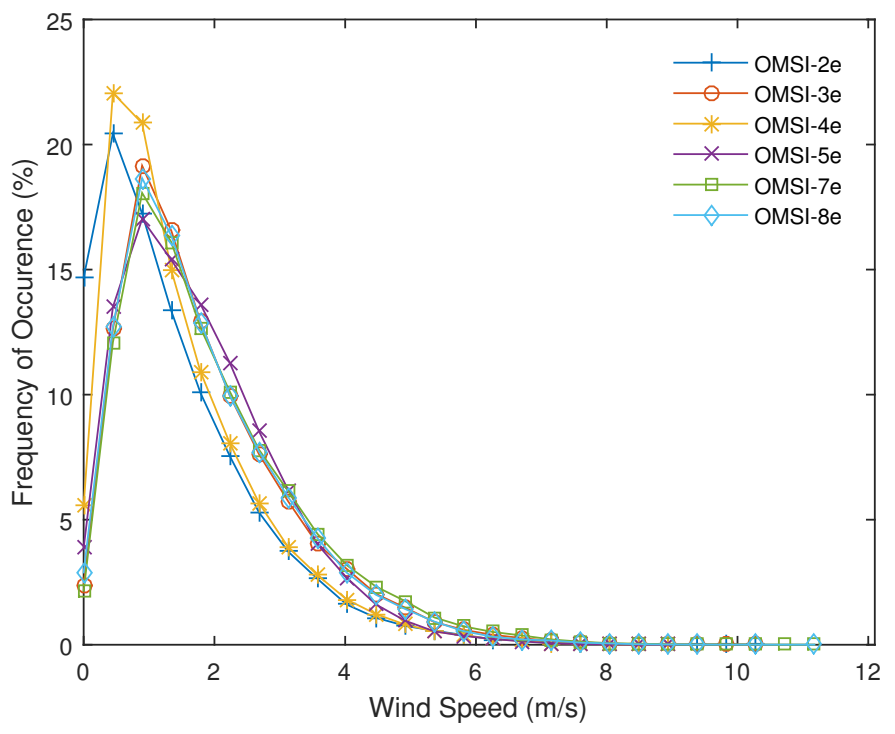

(B) East stations

Figure 4.1: Frequency distributions 


\subsection{Cumulative Probability Distribution}

Similar to the frequency distribution, Figure 4.2 shows cumulative probability distributions for the west and east sides of the bridge. Plotted are cumulative probability in percentage versus wind speed, with each profile representing a measuring station. For the western stations, SWF-3w, SWF-5w, and SWF-8w follow the same probability path. This points to consistency between measuring stations and emphasizes that they are experiencing the same wind conditions.

On the east side, OMSI-3e, OMSI-7e, and OMSI-8e have the same probability path. These stations are located on the Northern side of the approach (Figure 3.2(C)). OMSI-2e and OMSI-4e follow a secondary path and are on the southern side. Figure $3.2(\mathrm{C})$ shows these two stations are in very close proximity to one another and the Portland Opera building. OMSI-5e is also on the southern half of the eastern approach, but uniquely it does not follow the probability path of the other two stations until wind speeds increase beyond $3.0 \mathrm{~m} / \mathrm{s}$. There is a distinct division in cumulative probability trends on the eastern approach, separating the stations on the northern and southern side. The southern stations are immediately next to the Portland Opera building near roof-top height, and this is likely providing the cause for the difference.

Common conditions for the western stations show that about $90 \%$ of the time wind speeds are $4 \mathrm{~m} / \mathrm{s}$ or less. On the east, about $90 \%$ of the time wind speeds are $3 \mathrm{~m} / \mathrm{s}$ or less, with some variation depending on the station. The northern stations see $90 \%$ of their wind speeds $\leq 3.5 \mathrm{~m} / \mathrm{s}$. The southern stations proximity to the Portland Opera building may work to reduce wind speeds. 


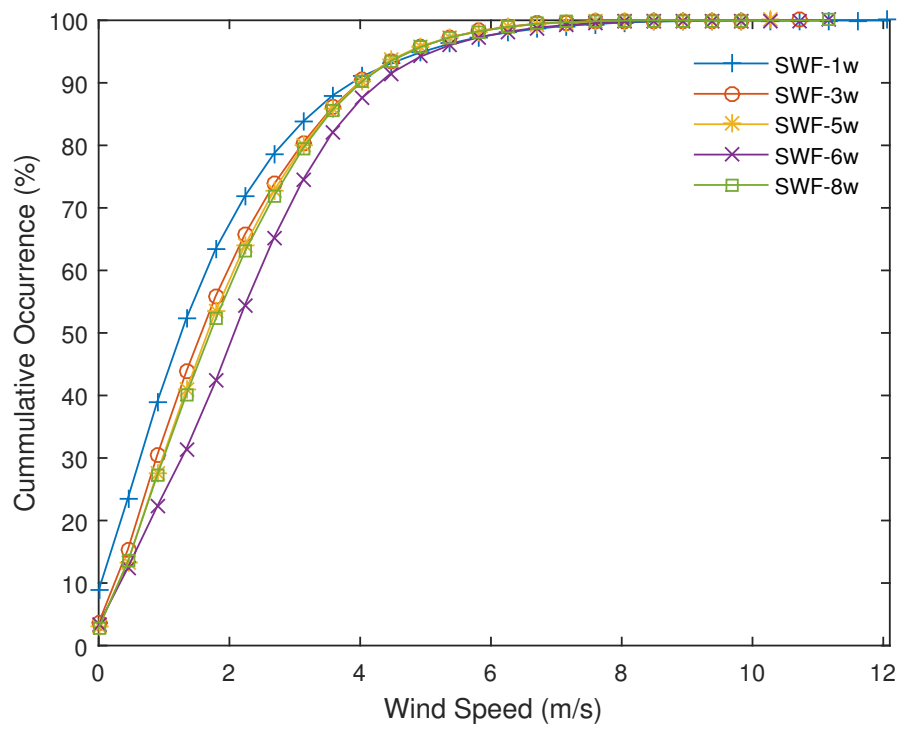

(A) West stations

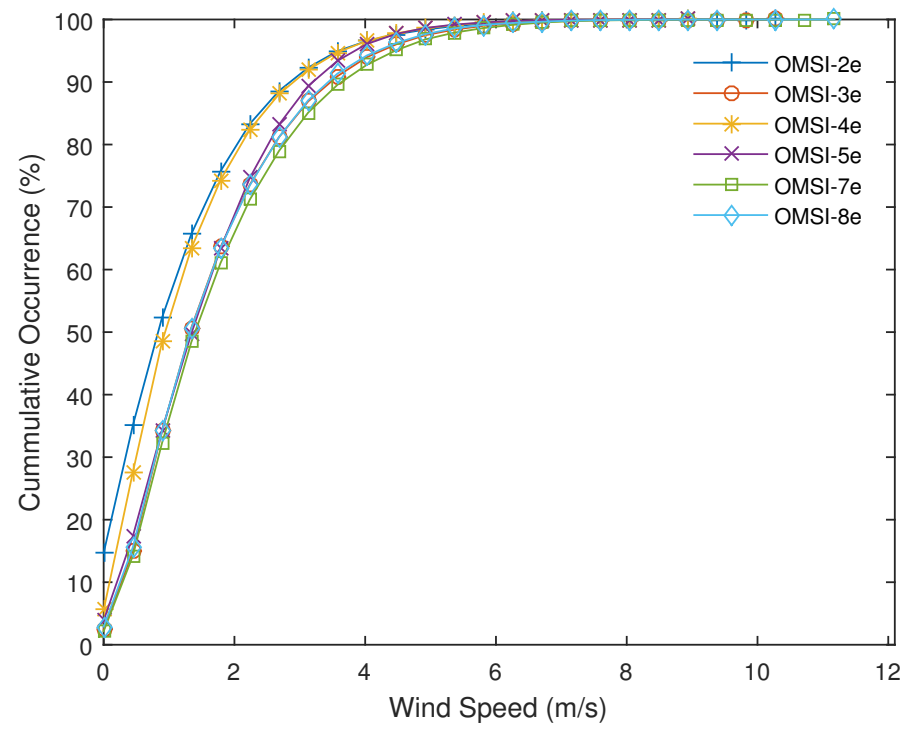

(B) East stations

Figure 4.2: Cumulative probability distributions 


\subsection{Wind Rose}

Wind roses are shown in Figure 4.3 for nine measuring stations. There is an overall trend for wind to come from the North and South for western stations. The five northern-most wind directions, NW, NNW, N, NNE, and NE, contain between 32 and $37 \%$ of total wind events, depending on the measuring station. The five southern-most wind directions, SW, SSW, S, SSE, and SE, contain between 41 and $48 \%$ of wind events, depending on the measuring station. Wind rarely comes from the East or West. Eastern wind roses show large radial arms coming from directly South. Between 49 and $53 \%$ of wind events come from the five southern-most wind directions. There are also small peaks in the NNW direction for the eastern stations containing between 9 and $11 \%$ of total wind events. Wind direction tends to follow the direction of the Willamette River channel. 


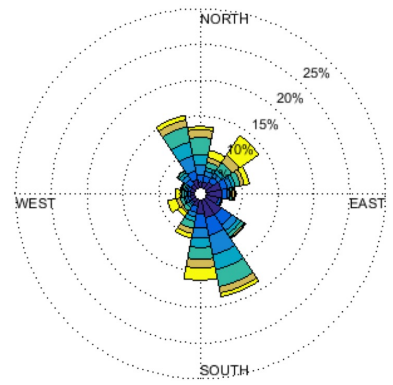

(A) SWF-1w

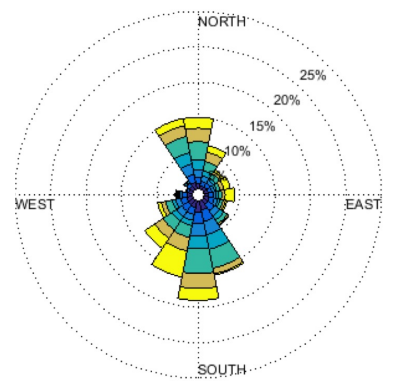

(D) SWF-8w

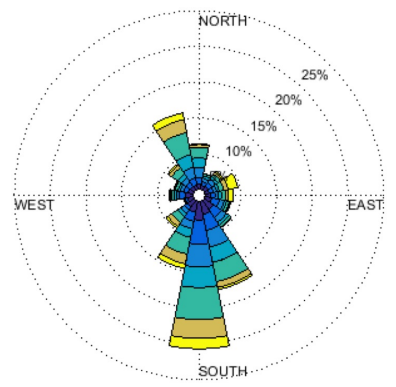

(G) OMSI-5e

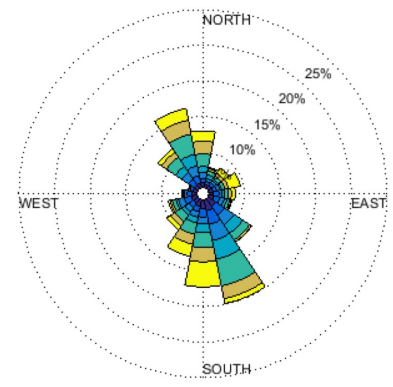

(B) SWF-5w

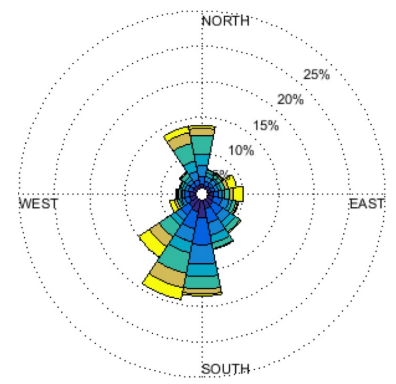

(E) OMSI-3e

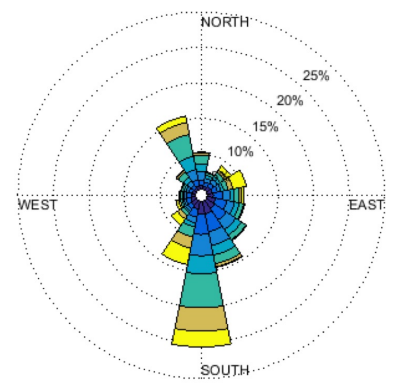

(H) OMSI-7e

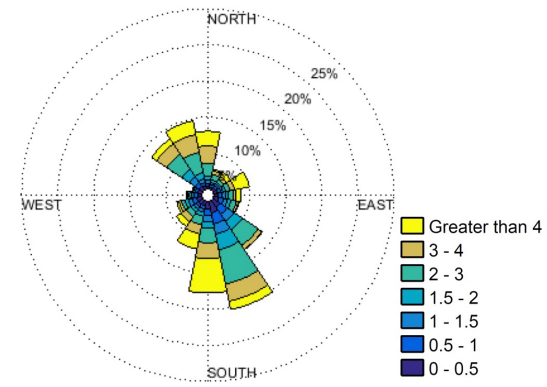

(C) SWF-6w

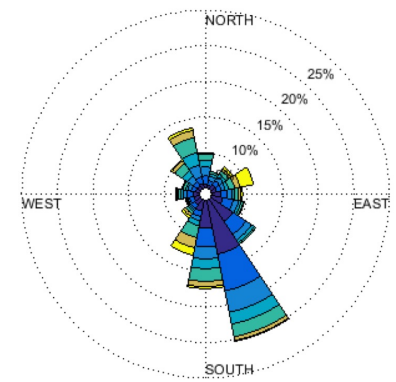

(F) OMSI-4e

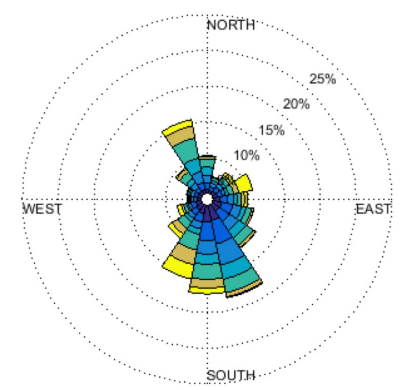

(I) OMSI-8e

Figure 4.3: Wind roses for nine measuring stations, four western and five eastern

\subsection{Correlation Matrix}

Figure 4.4 shows correlation matrices for west and east sides of the bridge, respectively. Western data comes from the weather station SWF-1w and eastern data 
from OMSI-2e. Plotted in the matrices are wind speed, temperature, pressure, and relative humidity along both the horizontal and vertical axis. Where variables intersect there is a color corresponding to their degree of correlation. Along the diagonal variables are correlated with themselves, resulting in a perfect positive correlation. Therefore, correlations above the diagonal are mirrored below.

Both matrices show a moderate negative correlation between relative humidity and temperature. As one variable increases, the other tends to decrease. This correlation is -0.46 on the west side and -0.48 on the east side. It is not a unique trend; relative humidity naturally decreases as temperature increases. There is also a small negative correlation for the eastern approach between relative humidity and wind speed with a value of -0.34 . The correlation is not present on the western approach.

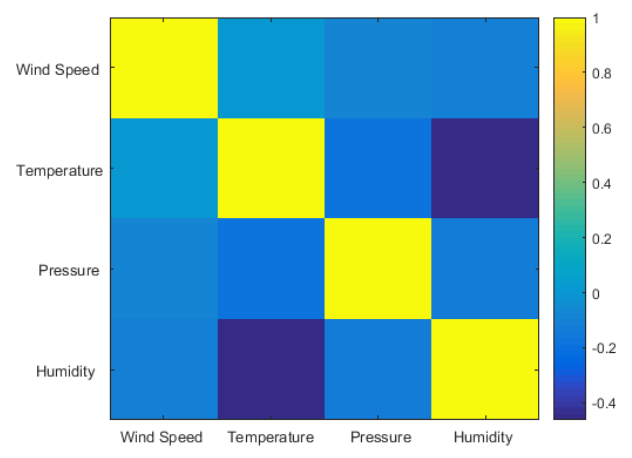

(A) West stations

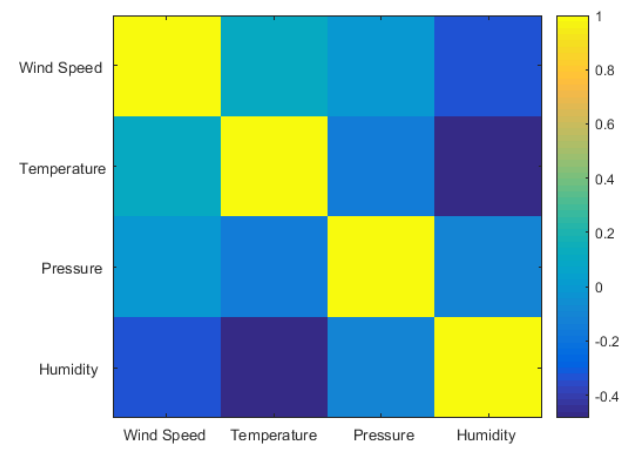

(B) East stations

Figure 4.4: Correlation matrix 


\subsection{Average Wind Speeds}

The average wind speed for all stations is recorded in Figure 4.5. Stations are placed on the horizontal axis and average wind speed on the vertical axis. Eastern averages range from 1.3 to $2.0 \mathrm{~m} / \mathrm{s}$ while western averages range from 1.9 to $2.5 \mathrm{~m} / \mathrm{s}$. Earlier observations pointed to OMSI-2e and OMSI-4e experiencing reduced speeds compared to northern stations on the eastern approach. Figure 4.5(B) confirms this observation showing about a $20 \%$ speed reduction for these two stations. On the west, SWF-6w uniquely experiences the highest average speed of all.

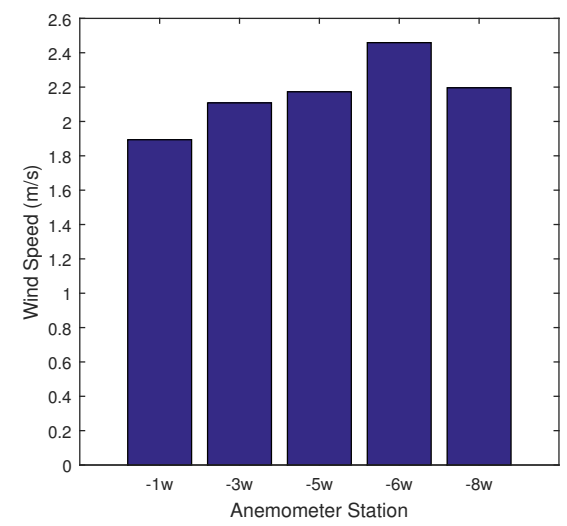

(A) West stations

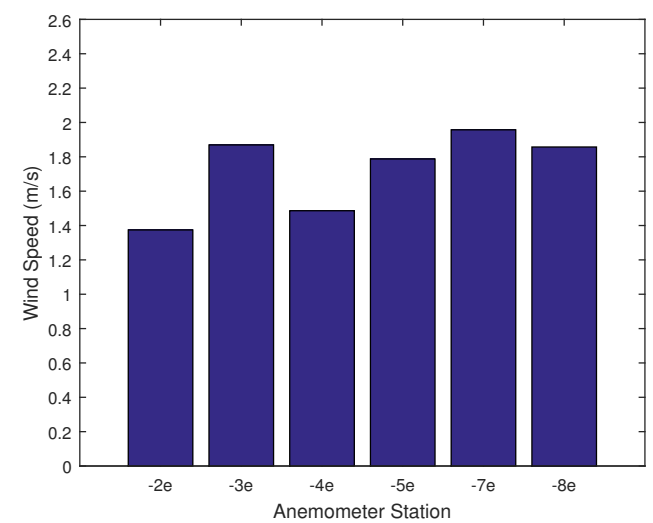

(B) East stations

Figure 4.5: Average wind speeds

Figure 4.6 breaks down average speed further into monthly intervals. Months of the year are plotted in the major segments of the horizontal axis and average wind speed on the vertical axis. Each major horizontal segment is further divided into minor segments representing individual measuring stations. From September to October there is a moderate drop in average monthly wind speed. But in November and December wind speeds increase once again. Then in January and February they 
drop to speeds similar to October, and in March, return to higher levels.

Focusing again on SWF-6w, Figure 4.6(A) shows it having the highest average speeds for each month. The western approach to the bridge is a relatively unabstructed wind environment, making the high speeds observed at SWF-6w less likely due to geographic and structural obstacles. It is more likely that it has manufacturing or calibration differences not present in the other instruments.

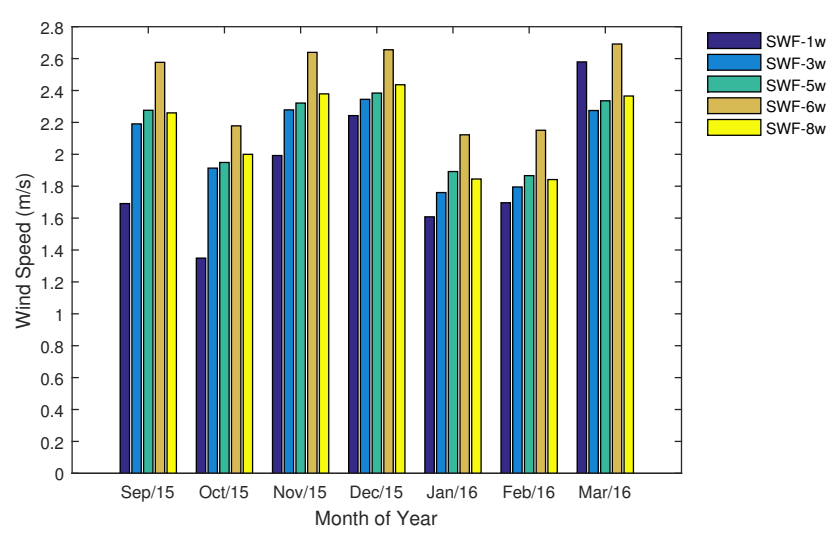

(A) West stations

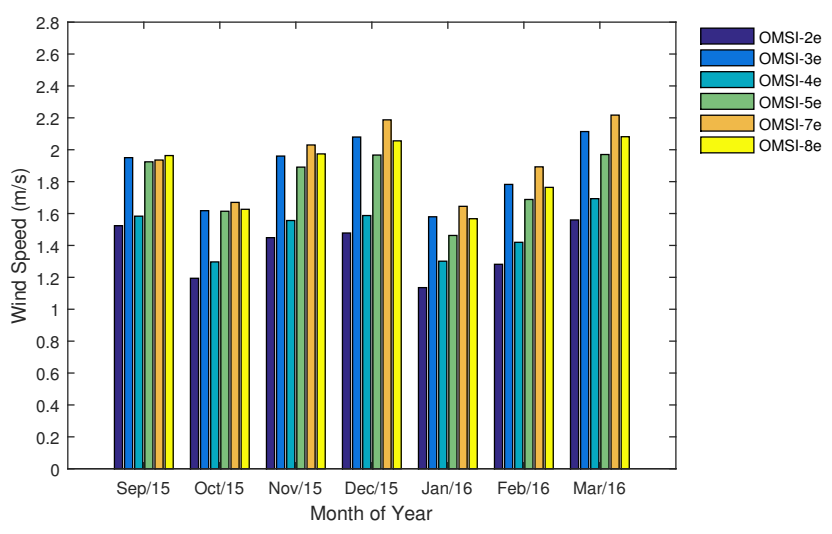

(B) East stations

Figure 4.6: Monthly average wind speeds 


\subsection{Diurnal Cycle}

For the diurnal cycle shown in Figure 4.7, wind speed is plotted versus time in hours of the day. Each line represents a single measuring station: western stations shown as solid lines, eastern stations as dash-dotted lines. A uniform trend is present for all stations. From midnight to 6:00 wind speeds decrease slightly. Then, from 6:00 to about 10:00 wind speed begins to increase rapidly, and continue to increase until about 14:00 when highest magnitudes are reached. From there wind speed drops at a constant rate until 19:00, with some stations picking up a little speed on the way to 24:00. On average wind speeds will be higher during the day than during the night, usually increasing by about $44 \%$ over the nighttime low. Similar to the average wind speeds, the diurnal cycles for western stations have higher wind speeds than eastern stations.

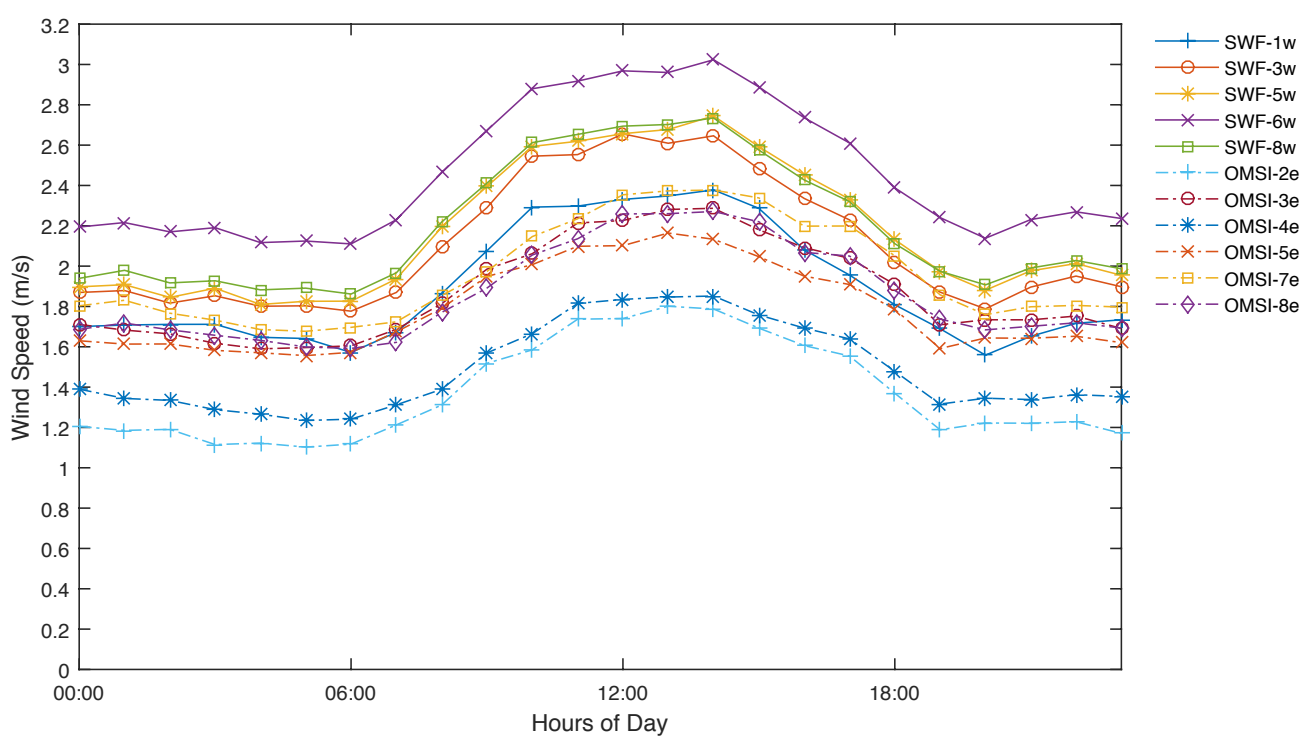

Figure 4.7: Diurnal cycle 


\subsection{Turbulence Intensity}

Generally for turbulence intensity, values of 0.1 or less correspond to low turbulence, 0.1 to 0.25 to moderate turbulence, and greater than 0.25 to high turbulence for a location [20]. Based on these ranges, Figure 4.8 shows that all stations experienced high turbulence. For both graphs, the weather stations have the highest TI values, as large as about 0.6 on the east. Conversely the anemometers are much more consistent with TIs between 0.35 and 0.40 . This disparity highlights a potential difference in how the two instrument models measure wind.

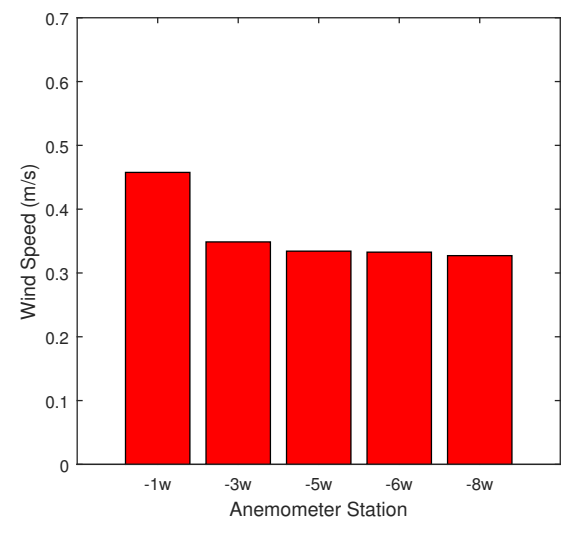

(A) West stations

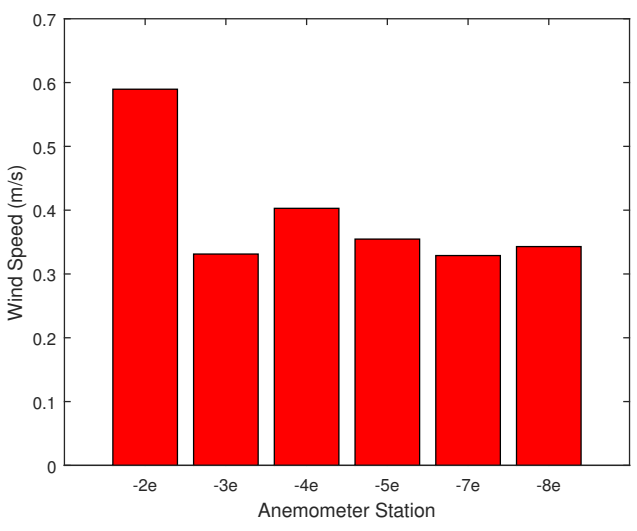

(B) East stations

Figure 4.8: Turbulence intensity 


\section{Chapter 5}

\section{Conclusion}

TriMet intends to install VAWTs on the Tilikum Crossing bridge in Portland, Oregon. Prior to installation a wind resource assessment was performed on the bridge to characterize the wind resource available for energy production. 12 measuring devices were placed on the approaches to the bridge with six on either side. Each approach was equipped with a weather station and five cup anemometers. Data was recorded for seven months from September 2015 through May 2016. Anemometers on the western side of the bridge experienced data recording issues resulting in omission of $15 \%$ of total data recordings. Wind speed, wind direction, and weather variables were analyzed in order to understand the present wind environment.

Frequency distributions showed the most frequently occuring wind speeds were between 0 and $2 \mathrm{~m} / \mathrm{s}$, with calm conditions occuring about $3 \%$ of the time. Wind speeds were below $4 \mathrm{~m} / \mathrm{s}$ about $90 \%$ of the time and rarely increased above $6 \mathrm{~m} / \mathrm{s}$. For measuring stations on the east side of the bridge, average wind speeds were between 1.3 and $2.0 \mathrm{~m} / \mathrm{s}$, for the west they were between 1.9 and $2.5 \mathrm{~m} / \mathrm{s}$. Average speeds were relatively constant from month to month with minimal decreases in speed during October, January, and February. For the daily wind cycle however, speeds were lowest during the nighttime hours and increased by about $44 \%$ during 
the daytime hours. Peaks were reached around 2:00 PM in the afternoon. Regarding turbulence, all measuring stations show high average levels of turbulence intensity meaning speeds were frequently changing. Wind direction came primarily from the South, accounting for between 41 and $53 \%$ of all wind recordings. Western stations also experienced a high volume of wind from the North, about $35 \%$ of wind recordings. Weather variables like temperature, humidity, and air pressure showed no distinct correlation with wind speed.

Focusing on the eastern measuring stations, there is an observable speed difference between stations on the northern and southern half of the approach. Southern stations experience $20 \%$ lower wind speeds than the northern stations. The Portland Opera building is adjacent to the eastern approach, in very close proximity to the southern measuring stations, and the building acts as an obstruction to wind causing the reduced speeds.

Considering all aspects, the wind resource on the Tilikum Crossing is lacking. Average wind speeds are low. This presents a significant obstacle when planning for the available wind resource to power wind turbines. Even small wind turbines, with low cut-in speeds, will seldom encounter wind speeds strong enough to generate power. 


\section{Bibliography}

[1] S. Rehman and N. M. Al-Abbadi, "Wind shear coefficient, turbulence intensity and wind power potential assessment for dhulom, saudi arabia," Renewable Energy, vol. 33, no. 12, pp. 2653 - 2660, 2008.

[2] U. E. I. Administration, "Monthly energy review april 2016," 2016.

[3] A. Neslen, "Denmark broke world record for wind power in 2015."

[4] G. W. E. Council, "Global wind 2015 report: Annual market update," 2015.

[5] A. W. E. Association, "Small wind."

[6] A. W. E. Association, "Faqs for small wind systems."

[7] G. Müller, M. F. Jentsch, and E. Stoddart, "Vertical axis resistance type wind turbines for use in buildings," Renewable Energy, vol. 34, no. 5, pp. 1407 1412, 2009.

[8] M. Casini, "Small vertical axis wind turbines for energy efficiency of buildings," Journal of Clean Energy Technologies, vol. 4, no. 1, 2016.

[9] TriMet, "Portland-milwaukie light rail transit project sustainability report," March 2015.

[10] T. Burton, Wind energy handbook. Chichester, West Sussex : Wiley, 2nd ed., 2011.

[11] M. Nedaei, "Wind energy potential assessment in chalus county in iran," International Journal of Renewable Energy Research, vol. 2, no. 2, pp. 338-347, 2012.

[12] F. A. Jowder, "Wind power analysis and site matching of wind turbine generators in kingdom of bahrain," Applied Energy, vol. 86, no. 4, pp. $538-545$, 2009. 
[13] I. Janajreh, L. Su, and F. Alan, "Wind energy assessment: Masdar city case study," Renewable Energy, vol. 52, pp. 8 - 15, 2013.

[14] M. Gökçek, A. Bayülken, and Ş. Bekdemir, "Investigation of wind characteristics and wind energy potential in kirklareli, turkey," Renewable Energy, vol. 32, no. 10 , pp. $1739-1752,2007$.

[15] A. Ucar and F. Balo, "Evaluation of wind energy potential and electricity generation at six locations in turkey," Applied Energy, vol. 86, no. 10, pp. $1864-$ 1872, 2009.

[16] P. Saengyuenyongpipat, "Refworks export demonstrating measure-correlatepredict algorithms for estimation of wind resources in central finland," Master's thesis, University of Jyväskylä, 2010.

[17] E. Elena, "Wind characteristics and wind potential assessment for braşov region, romania," International Journal of Science and Engineering Investigations, vol. 3, April 2014.

[18] K. M. Sunderland, G. Mills, and M. F. Conlon, "Estimating the wind resource in an urban area: A case study of micro-wind generation potential in dublin, ireland," Journal of Wind Engineering and Industrial Aerodynamics, vol. 118, pp. $44-53,2013$.

[19] B. Karthikeya, P. S. Negi, and N. Srikanth, "Wind resource assessment for urban renewable energy application in singapore," Renewable Energy, vol. 87, Part 1, pp. 403 - 414, 2016.

[20] I. AWS Scientific, Wind resource assessment handbook : fundamentals for conducting a successful monitoring program. Golden, CO : The Laboratory ; Springfield, VA : National Technical Information Service, distributor, 1997.

[21] N. W. Service, "Climate of portland."

[22] N. W. S. F. Office, "Portland metro area elevations." 